\title{
Disinfection Measures for COVID-19
}

\author{
Ketki Fuladi ${ }^{1}$, Dr. Swaroopa Chakole ${ }^{2}$ \\ Type of Article: Review \\ Conflict of Interest: None \\ Funding: DMIMS \\ Ethical Approval: IEC, DMIMS, Wardha.
}

${ }^{1}$ Intern, Dept. of Community Medicine, Jawaharlal Nehru Medical College, Datta Meghe Institute of Medical Sciences (Deemed to be University), Sawangi (Meghe), Wardha-442001, Maharashtra, India,

${ }^{2}$ Professor, Dept. of Community Medicine, Jawaharlal Nehru Medical College, Datta Meghe Institute of Medical Sciences (Deemed to be University), Sawangi (Meghe), Wardha-442001, Maharashtra, India, emails: ${ }^{1}$ ketkifuladi@gmail.com, ${ }^{2}$ drswaroopachakole@gmail.com,

\begin{abstract}
BACKGROUND

COVID-19 or coronavirus disease 2019 is seriously affecting the day-to-day life of all the people on the Earth. The lethal nature and high virulence are the key factor that are adversely affecting the mitigation measures.

\section{SUMMARY}

Extreme uncertainty attached to the COVID-19 is a challenge that is faced by health care professionals and governmental agencies in controlling the viral spread. The virus can sustain inside and outside the body for considerable amount of time. Coronavirus can survive on many surfaces and can create menace. Therefore, it is necessary to assess the situation and certainly act upon it. Disinfection measures are the best suited for containment of the virus.
\end{abstract}

CONCLUSION

More study needs to be done in order to assess the benefits of disinfection measures.

KEYWORDS:COVID-19, Preventive measures, disinfection, Isopropyl alcohol, sanitizer, containment

\section{INTRODUCTION}

Coronavirus disease 2019 or COVID-19 is the viral disease outbreak which is raging across the globe. The unprecedented nature of the pandemic is proving deadly for all of humanity. Existential threat has been created by the human coronavirus which is also known as novel coronavirus.(1) SARS-COV-2 which is the upgraded form of SARS-COV which had caused the 2003 SARS epidemic in several part of the world. The unprecedented nature of the disease outbreak can be felt from the figures attached to it. As of January 12, 2021, 91,266,225 people are infected from the coronavirus disease 2019 or COVID-19 and case fatalities touching two million mark and stands at $1,953,866(2)$. The case fatality rate is between one to two percent average being 1.5 percent. This is way less than the case fatality rates of previous outbreaks of severe acute respiratory syndrome (SARS) and middle eastern respiratory syndrome (MERS), where case fatality rate was as high as 10 percent and 35 percent respectively. But the extent of the novel coronavirus exceeds the coverage of the SARS and MERS outbreaks(3). United states of America, India, Brazil, Russian federation, France and United Kingdom are the top countries having highest viral infections. These countries only accounts for more than half of infected cases and case fatalities happening around the world(4). The extremely high virulent nature and attached fatal clinical outcomes has forced the World Health Organization (WHO) to declare the COVID-19 as pandemic upgrading its status from public health emergency of international concern (PHEIC)(5). Comorbidity is the biggest decider in terms of clinical outcomes of the patient. Comorbid patient has more chance of developing severe clinical outcomes than their non-comorbid 
counterparts(6). In fact, more nurses have died during the COVID-19 duty and by COVID-19 related complications than in FirstWorld War(7). Also, many healthcare professionals such as doctors and allied health care workers were also laid their life serving in the line of duty. Various preventive and mitigation measures are being implemented to curb the spread of the virus. Disinfection measures are one of them. Various surfaces can harbor the novel coronavirus or SARS-COV-2 for considerably long time. There it is important to ensure extermination of the virus from such surfaces especially when there are number of touches are more. This includes public places such as airports, railway junction and many more. Other safe practices include hand hygiene and sanitization at regular interval so that they remain germ and virus free. Transmission through hand to mouth or nose has been noticed very often. In this article these points are comprehensively reviewed asan overview has been taken to understand the correlation among several factors.

\section{DISINFECTION MEASURES COVID- 19}

COVID-19 or coronavirus disease 2019 is an extremely infectious viral infection that is creating ruckus all acrossthe world. The high virulent nature and capacity of producing critical clinical outcomes makes the novel coronavirus lethal. The containment of the virus is extremely difficult. Human to human transmission takes place rapidly and with less efforts. Therefore, it is the need of the hour to contain the virus by applying all the options available. Infection caused due to novel coronavirus should be prevented from happening at the first place than treating it. Various adverse aspects are attached to the clinical treatment of the COVID-19 and there are also many longterm implications. Psychological impact has been seen among varioussections of population and it is needed to be addressed. Preventive measures are best suited for pandemic like COVID-19 and it needs to be reinforced. Disinfection is the main factor through which COVID-19 or coronavirus disease 2019 spread can be curbed(8).Disinfection measures includeswide range of activities that must be done in order to achieve considerable amount of reduction of newly infected cases. Various places can sustain the virus for very long time and can increase the spread of the disease as people will touch these surfaces. COVID-19 care facilities and hospitals treating the disease are the key elements of test, trace and treat strategy. These must be following protocols that is issued by competent health authority in order to maximize the mitigation measures output. A pan country standard protocol must be issued which will be then easy to monitor and enforced. This will act as force multiplier in the mitigation strategy.Establishment of safety protocol which should be containing the proper contiguous directions about various containment measures. This includes disinfection, physical distancing measures, hygiene, personal protective equipment usage like wearing masks, face shields and so many more. Various places are known to harbor viruses on them for considerable amount time. Various infrastructural facilities such as COVID-19 care facilities and hospitals which are dedicated for treatment of the disease outbreak are in itself hotspots for spreading more infection through its visitors. Hospitals which are dedicated for COVID-19 containment are the most infectious place where infected patients are placed according to the severity of the disease of COVID-19. Family members accompanying the patient are vulnerable to watch the infection. The hospital staff also have to work in the extremelyvulnerable environment(9). The COVID-19 or coronavirus disease 2019, and how it ransacked the present health care systems along with lives of the people is the best example to be feared for. It is necessary to safeguard the doctors and health care professionals and allied health 
workers as their number to the population they are serving ratio is low in almost all the countries. Already they are stressed with over burdening of their duty and huge amount of patient's influx. And now COVID-19 is proving the worst nightmare of the whole world's life. Various public places such as travelling junction, bus station, aerodrome, air traffic points or airports are the potential hotspots as these places harbor more footfalls than any other places. Also, religious places and pilgrimage sites across the world attracts many pilgrims and devotees. There is no chance of maintaining or following the physical distancing norms as these places are already congested and have less space for performing and maneuveringexercise. Regular disinfection of these sites is the need of the hour after gradual opening up of the economy and people are going back to normal life again. Governmental and private offices are allowed to work at half strength and in private sector such as information and technology where the job or the nature of work can be fulfilled from a computer machine or personal computer, there work from home has been started so that employees do not gather at office complex as they were doing in pre COVID-19 era(10). Only the support staff for various necessary and requires maintenance job were continued to go to their workplaces as it was inevitable for them. Only essential service providers and associated staffs were allowed to go to workplaces. This has reduced the contact time among people from various places and also reduced the chances of getting infected.

Preventive measures are necessary in order to deal with the pandemic in an efficient way. Various mitigation measures are issued and by World Health Organization (WHO) and other competentregional health care authorities in order to guide the efforts of containment of the coronavirus disease $2019 . \quad$ Non pharmacologicalinterventionwas not meant for sustaining for long time and it was inevitable to issue new measures(11). The non-coercive measures are the best as they are easily adopted by public and population at large without being enforced. Only proper promotion and efficacy should be needed in order to make people aware about these available measures for thecontainment of COVID-19. Wearing of masks, maintain safe minimum physical distance while in public, sanitizing of hand at regular intervals are some of the effective measures which are highly popularize after the arrival of the pandemic. The measures will not only help in the containment of the COVID-19 and curbing its spread but other noncommunicable disease such as flue and otherinfluenza like illnesses (ILI) are also prohibited from spreading if the measures are followed properly(12).

The disinfection part of the mitigation measures requires governments as well as residents and citizens participation in order to succeed in its purpose of implementation. Disinfection means cleaning and disinfecting a surface. It can be a hand where virus can stay for long time as well as from there it can transmit to other parts of the body organ such as lungs. Public places have lots and lots of surfaces which are common to all and are touched by many people. It can act as transmitting agent for various other people who touches it after an infected person touches a surface and leaves the viral load. Also spitting at public places is extremely bad habit and can accelerate the disease transmission of not only coronavirus disease 2019 or COVID-19 but also various other communicable disease which spreads through either droplet or direct contacts. The main hotspots or places which are high in touch counts are faucets, handrailing's, knobs on door, light switches, kitchen appliances, sharedequipment's such as computers and laptops at public places such as cybercafé and so many places which needs time to timedisinfection and cleaning. One specific time must be decided to disinfect 
and clean the said place. The frequency can be decided after considering the number of instances of touches and time of opening(13).

\section{EQUIPMENT'S AND KITS TO CLEAN SURFACES}

Visibly dirty surfaces support various harmful lifeforms which can be lethal to human beings if entered in to the human system. Majordamage can occur if the surfaces are not cleaned on regular interval. Soaps and detergents along with the soap water can be used to disinfect the clean the place thoroughly. The purity and effectiveness of the disinfectant must be approved by competent authority dealing with chemicals and associated things. Which will further ensure the cleanliness and effectivity of the disinfectants. Approved products are more trusted and hence can be used with no harm intended. Safe and effective usage also means proper use of chemicals. Various forms and concentration can be used such as diluted or concentrated according to the need of the situation. Application method and time of application can be varied and necessary precaution can be taken in order to reap the full benefits of the measures. Contact time and concentration of disinfectant are the deciding factor in effectively clean the surface. Safety in handling the disinfectants and other chemicals used for cleaning purpose and sanitization must be paramount and the preparation area must be well ventilated and aerated. This important so as to reduce the exposure of the fumes or other gases and chemicals to the handling personals. Timely renewal and feedback about the effectiveness must be noted in order to establish the relation between chemicals efficacy and its usage. There are certain restrictions while using inflammable stuff near electronics and associated with them. Inflammable liquid might catch fire if used near electrical equipment's. Wipeable cloth or covers are best suited to wipe of the keyboards and other input devices. It will truly disinfect the said surfaces. Spray also can be used in order to disinfect the surface. Bleach solution of two to three percent also found to be effective. This includes thousands part per million (1000 ppm) of chlorine which is also already in use as disinfectant in various pools and algae areas. Alcohol of seventy percent can be used for variouspurpose. But stocking it in more than 10 gallons would be harmful and can ignite fire. In case of soft and porous material like rugs, carpeted floor, fabric floor, the first thing should be cleaningthe floor withwhichever thing one wanted to. Several directionsare needed to be followed in order safeguard the person who is spreading the disinfectants(14).

\section{HAND HYGIENE}

The latest pandemic COVID-19 has contributed to a global understanding of hand hygiene and hand cleansing. During the COVID-19 pandemic, handwashing gained considerable publicity. Hand hygiene is a generally recognized concept for preventing the spread of diseases, since good hand hygiene is likely to decrease transmissible disease by between 24 and 31 percent. COVID-19 is an enfolded, non-segmented, positively-sensitive RNA virus that is caused by extreme acute coronavirus 2 respiratory syndrome (SARS-CoV-2). The virus is believed to distribute through direct contact, indirect contact and droplet contact, according to Centres for Disease Control and Prevention (CDCs). HCWs must stick to the 'My 5 Moments for Hand Hygiene' of the WHO: prior to actually patient contact, prior sterile or disinfect interventions, after contact to or danger of body fluid, after patient contact and after contacting the area of the patient. To avoid viral transmission, the $\mathrm{CDC}$ suggests regular hand washing for 20 seconds with soap and water; otherwise, a hand sanitizer containing at least 60 percent alcohol may be employed if soap and water are not available(16). 
In various forms, hand hygiene products are available: solvent or bar cleansers, cleaning fluids, antimicrobial handwashes, and hand sanitizers based on alcohol.

Forms of Commodities For HAND Sanitation

Soap

This is more efficient form of hygiene for hand than hand sanitizer, there is evidence to support soap. The added advantage of physically washing removes dirt and pollutants with flowing water is hand washing with soap and water. Debris are remove by soap, andlipids which are intracellular beneficiated are also removed and proteins present in the skins layer stratum corneum are destroyed.

Synthetic Detergent

Petrolatum-based synthetic detergents combined with surfactants which are weaker than 10 percent and will have a $\mathrm{pH}$ from 5.5 to 7 , equivalent to $\mathrm{pH}$ in good and safe skin.There are chemical surfactants in synthetic detergents, which operate similarly to soap.With the destruction of viruses surrounded on the lipid and much of the protozoa, synthetic detergents have been shown to be successful. They are, however, ineffective against viruses enveloped by non-lipids. Therefore, COVID-19, a virus which surrounded by lipid structure, is susceptible to detergent which are synthetic in nature .

Alcohol Base Hand Sanitizer

The Alcohol Base Hand Sanitizer acts to denature and coagulate proteins by breaching the viral membrane, disrupting cellular metabolism and causing viral particle lysis.

Disinfectant Wipes

By destroying the viral membrane, COVID-19 virus break by the hand wipes which contain antimicrobial ingredients. Likewise, in the same process as ABHS, alcohol-based hand wipes often degrade the integrity of the viral membrane, rendering them a viable opponent of COVID-19.

Steps for Hand Wash
1. Hands wet with running water

2: To cover wet palms, add enough soap

3: Scrub all hand surfaces for at least 20 seconds, including the dorsal of the hands, fingers web space and under the nails(18).

4: Thoroughly rinse with water flow

5: With a clean cloth or single-use towel, dry hands

There has been a proliferation of public health messages regarding the value of handwashing, and the proper handwashing methods, through different outlets. Memes and short videos are all in use to reach people on their mobile computers, as well as through social media and popular television, radio, print advertising and billboards, all with the same message of efficient handwashing.

A number of related studies were reported from this region (19-21). Useful studies on prevention of spread of infection were reported (22-25). Khatodet. al.(26) and Dhole et. al. (27) discussed on disinfection in dentistry. Late et. al. elaborated on protocol for handling and disposal of the dead bodies in Covid-19 (28).

\section{CONCLUSION}

Preventive measures are best suited for the COVID-19 pandemic as several complications are attached to it. Disinfection as a part of the mitigation measure may prove extremely effective if properly used and utilized. Necessaryprecaution while handling the chemicals and other disinfectants must be taken in order to ensure the safety of the handling agent. Timing, quantity ad concentrations are also key to ensure maximum benefits form the methods.

\section{REFERENCES}

1. Dushyant Bawiskar, Pratik Phansopkar, Ayurva Vilas Gotmare. COVID-19 Facets: Pandemics, Curse and Humanity. Int J Res Pharm Sci. 2020 Aug 6;11(SPL1):385-90.

2. COVID-19 Map [Internet]. Johns Hopkins Coronavirus Resource Center. [cited 2021 Jan 13]. 
Available from: https://coronavirus.jhu.edu/map.html

3. Ngai JC, Ko FW, Ng SS, To K-W, Tong M, Hui DS. The long-term impact of severe acute respiratory syndrome on pulmonary function, exercise capacity and health status. Respirol Carlton Vic. 2010 Apr;15(3):543-50.

4. WHO Coronavirus Disease (COVID19) Dashboard [Internet]. [cited 2021 Jan 13]. Available from: https://covid19. who.int

5. WHO Director-General's opening remarks at the media briefing on COVID-19 - 11 March 2020 [Internet]. [cited 2021 Jan 12]. Available from: https://www.who.int/directorgeneral/speeches/detail/who-directorgeneral-s-opening-remarks-at-themedia-briefing-on-covid-19---11march-2020

6. Fang X, Li S, Yu H, Wang P, Zhang $\mathrm{Y}$, Chen Z, et al. Epidemiological, comorbidity factors with severity and prognosis of COVID-19: a systematic review and meta-analysis. Aging. 2020 Jul 13;12(13):12493-503.

7. ICN confirms 1,500 nurses have died from COVID-19 in 44 countries and estimates that healthcare worker COVID-19 fatalities worldwide could be more than 20,000 [Internet]. ICN International Council of Nurses. [cited 2021 Jan 12]. Available from: https://www.icn.ch/news/icnconfirms-1500-nurses-have-diedcovid-19-44-countries-and-estimateshealthcare-worker-covid

8. Tysiąc-Miśta M, Dubiel A, Brzoza K, Burek M, Pałkiewicz K. Air disinfection procedures in the dental office during the COVID-19 pandemic. Med Pr. 2020 Oct 16;

9. Kory P, Meduri GU, Iglesias J, Varon J, Marik PE. Clinical and Scientific Rationale for the "MATH+" Hospital Treatment Protocol for COVID-19. J
Intensive Care Med. 2021

Feb;36(2):135-56.

10. COVID-19 Working Well Protocols | Infectious Diseases [Internet]. [cited 2021 Jan 10]. Available from: https://www.bumc.bu.edu/id/covid19-response/covid-19-working-wellprotocols/

11. COVID-19-Clinical-ProtocolsAECS.pdf [Internet]. [cited 2021 Jan 10]. Available from: https://www.iapb.org/wpcontent/uploads/COVID-19-ClinicalProtocols-AECS.pdf

12. Güner R, Hasanoğlu I, Aktaş F. COVID-19: Prevention and control measures in community. Turk $\mathbf{J}$ Med Sci. 2020 Apr 21;50(SI-1):571-7.

13.

Guidelinestobefollowedondetection ofsuspectorconfirmedCOVID19case. pdf [Internet]. [cited 2021 Jan 10]. Available from: https://www.mohfw.gov.in/pdf/Guide linestobefollowedondetectionofsuspe ctorconfirmedCOVID19case.pdf

14. Tarantini Giuseppe, Masiero Giulia, Nai Fovino Luca. Impact of a 10 Rules Protocol on COVID-19 Hospital-Related Transmission. Circ Cardiovasc Interv. 2020 May 1;13(5):e009279.

15. Lotfinejad N, Peters A, Pittet D. Hand hygiene and the novel coronavirus pandemic: the role of healthcare workers. J Hosp Infect. 2020 Aug;105(4):776-7.

16. Shi Y, Wang G, Cai X-P, Deng J-W, Zheng L, Zhu H-H, et al. An overview of COVID-19. J Zhejiang Univ Sci B. 2020 May;21(5):343-60.

17. Rundle CW, Presley CL, Militello M, Barber C, Powell DL, Jacob SE, et al. Hand hygiene during COVID-19: Recommendations from the American Contact Dermatitis Society. J Am Acad Dermatol. 2020 Dec 1;83(6):1730-7.

18. When and How to Wash Your Hands Handwashing | CDC [Internet]. 
2020 [cited 2021 Jan 13]. Available from:

https://www.cdc.gov/handwashing/w hen-how-handwashing.html

19. Khatib, M.N., S. Gaidhane, M. Khatib, M. Ahmed, A. Gaidhane, and Z.Q. Syed. "SARS-CoV and SARSCoV-2: Similar Viruses with Different Trajectories."

WutanHuatanJisuanJishu 16, no. 5 (2020): 544-48.

20. Gaidhane, S., N. Khatib, Q.S. Zahiruddin, A. Gaidhane, S. Telrandhe, and P. Godhiwal. "Depression, Anxiety and Stress among the General Population in the Time of COVID-19 Lockdown: A Cross-Sectional Study Protocol." International Journal of Research in Pharmaceutical Sciences 11, no. Special Issue 1 (2020): 360-64. https://doi.org/10.26452/ijrps.v11iSPL 1.2726 .

21. Nisargandha, M.A., and S. Dadaraoparwe. "Spread of Coronavirus Disease 2019 (COVID19) during the Lockdown in the Indian Population and Preventive Measures." International Journal of Research in Pharmaceutical Sciences 11, no. Special Issue 1 (2020): 328-32. https://doi.org/10.26452/ijrps.v11iSPL 1.2721 .

22. Rajput, D.S. "Evolution, Ayurveda, Immunity, and Preventive Aspects for Emerging Infectious Diseases Such as COVID-19." International Journal of Research in Pharmaceutical Sciences 11, no. Special Issue 1 (2020): 86-93. https://doi.org/10.26452/ijrps.v11iSPL 1.2227 .

23. Sharma, D. "Preventive Measures for COVID-19 Health Care Professionals." International Journal of Research in Pharmaceutical Sciences 11, no. Special Issue 1 (2020): 130712.

https://doi.org/10.26452/ijrps.v11iSPL 1.3626 .
24. Deshpande, A.M., and M.A. Deshpande. "Role of RasayanChurna in Outbreak of COVID-19 as Preventive and Curative Aspect." International Journal of Research in Pharmaceutical Sciences 11, no. Special Issue 1 (2020): 1208-12. https://doi.org/10.26452/ijrps.v11iSPL 1.3594 .

25. Deshpande, M.A., and A.M. Deshpande. "Preventive Measures for COVID 19 through Dincharya and Rutucharya Mentioned in Ayurvedic Text." International Journal of Research in Pharmaceutical Sciences 11, no. Special Issue 1 (2020): 239-45. https://doi.org/10.26452/ijrps.v11iSPL 1.2705 .

26. Khatod, S., A. Ikhar, P. Nikhade, and K. Khatod. "Preventive Measures for Dental Professionals during Worldwide Emergency COVID-19." International Journal of Research in Pharmaceutical Sciences 11, no. Special Issue 1 (2020): 150-53. https://doi.org/10.26452/ijrps.v11iSPL 1.2294.

27. Dhole, P.D., V.K. Lohe, R.P. Kadu, S.C. Mohod, M. Meshram, and G.A. Thakare. "Post COVID-19 Protocol of Treatment, Radiologic Examination and Infection Control in Dentistry." International Journal of Research in Pharmaceutical Sciences 11, no. Special Issue 1 (2020): 1384-89. https://doi.org/10.26452/ijrps.v11iSPL 1.3664.

28. Late, S.V., H. Keche, V.K. Chimurkar, and V. Anjankar. "Protocol for Handling and Disposal of the Dead Bodies in Covid-19." International Journal of Current Research and Review 13, no. 1 (2021): 7-9. https://doi.org/10.31782/IJCRR.2021.1 3102. 